\title{
Open issues on G3 neuroendocrine neoplasms: back to the future
}

\author{
Maria Chiara Zatelli1, Elia Guadagno², Erika Messina33, Fabio Lo Calzo4, Antongiulio Faggiano ${ }^{4}$ and \\ Annamaria Colao ${ }^{4}$ on behalf of NIKE Group
}

1Department of Medical Sciences, Section of Endocrinology and Internal Medicine, University of Ferrara, Ferrara, Italy 2Department of Advanced Biomedical Sciences, Pathology Section, University of Naples Federico II, Naples, Italy ${ }^{3}$ Department of Clinical and Experimental Medicine, University of Messina, Messina, Italy

${ }^{4}$ Department of Clinical Medicine and Surgery, Federico II University, Naples, Italy

Correspondence should be addressed to M C Zatelli: ztImch@unife.it

\begin{abstract}
The recent recognition that grade 3 (G3) neuroendocrine neoplasms (NENs) can be divided into two different categories according to the histopathological differentiation, that is G3 neuroendocrine tumors (NETs) and G3 neuroendocrine carcinomas (NECs) has generated a lot of interest concerning not only the diagnosis, but also the differential management of such new group of NENs. However, several issues need to be fully clarified in order to put G3 NETs and G3 NECs in the right place. The aim of this review is to focus on those issues that are still undetermined starting from the current knowledge, evaluating the available evidence and the possible clinical implications.
\end{abstract}

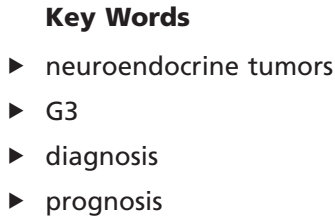
(2018) 25, R375-R384

\section{Introduction}

Neuroendocrine neoplasms (NENs) are well known to display a wide heterogeneity as concerns histopathology, clinical presentation, treatment and prognosis. Despite their rarity, NENs have drawn a lot of attention due to the newly available therapeutic approaches, that mainly depend on tumor stage and grade (Chan et al. 2017a,b, Cives \& Strosberg 2017, Finkelstein et al. 2017, Gallo et al. 2017, Hilal 2017, Lambrescu et al. 2017, Michael et al. 2017, Neychev \& Kebebew 2017, Rinke \& Gress 2017). Since cure is difficult to achieve in most aggressive forms, therapy is mainly aimed at delaying disease progression, in order to improve prognosis. The 2010 World Health Organization (WHO) classification considers neuroendocrine carcinomas (NECs) as a single category on the basis of a Ki-67 labeling index (LI) $>20 \%$ (Rindi et al. 2010). It has recently become apparent that the definition of NEC by the 2010 WHO classification includes a spectrum of different entities that are characterized by different prognosis and response to therapy, depending on tumor morphology (Welin et al. 2011, Vélayoudom-Céphise et al. 2013, Basturk et al. 2015, Heetfeld et al. 2015, Hijioka et al. 2015, Milione et al. 2017) and Ki-67 LI cut-off reassessment (Sorbye et al. 2013, Milione et al. 2017), suggesting the introduction of a new NEN category characterized by well-differentiated tumor morphology and Ki-67 LI $>20 \%$, indicated as G3 well-differentiated neuroendocrine tumors (NETs). This proposal underlines that $\mathrm{Ki}-67 \mathrm{LI}$ alone is not able to properly describe G3 NEN, which instead appears to be a heterogeneous category, and brings back the definition of these tumors to more morphological grounds, as indicated in the 2000 WHO classification.

\section{Aim}

The aim of this review is to summarize the available data on diagnosis, management and prognosis of G3 NETs and 
G3 NECs and to highlight the issues that are still open to debate in the scientific arena.

\section{Methodology}

Among the six authors, four (M C Z, E G, E M and F L C) independently searched MEDLINE (PubMed database) to detect articles published in the English language reporting on diagnosis and management of G3 NET and G3 NEC, excluding editorials and letters. The search was last updated 23 October 2017. Additional studies were identified by reviewing the references of all selected articles.

\section{Diagnosis}

According to the current WHO classification (Rindi et al. 2010), the diagnosis of G3 gastroenteropancreatic (GEP) NEN is based on the evaluation of proliferative activity (mitotic count $>20 / 10$ high power fields (HPFs) and/or $>20 \% \mathrm{Ki}-67 \mathrm{LI}$ ) and on cell size (large cell vs small cell). By definition, these are poorly differentiated tumors, whereby they are called NECs and can display two morphologic patterns (Figs 1 and 2). Grade 1 (G1) and grade 2 (G2) NETs are, instead, well-differentiated forms whose diagnosis relies only on Ki-67 LI and/or mitotic activity (NET G1: mitotic count $<2 / 10$ HPF and/or $\leq 2 \%$ Ki-67 LI; NET G2: mitotic count 2-20/10 HPF and/or 3-20\% Ki-67 LI). Recent evidence shows that G3 neoplasms represent a heterogeneous group of neoplastic proliferations, including both well- and poorly differentiated forms (Vélayoudom-Céphise et al. 2013, Basturk et al. 2015, Heetfeld et al. 2015, Tang et al. 2016a, Milione et al. 2017), with different prognosis and response to medical treatments (Sorbye et al. 2013). Based on these observations, a proposal for a new classification has been formulated, that consists of the combination of morphology and proliferative activity (Fig. 3), with the aim of a better prognostic stratification. Three new categories could be identified: NET G3, characterized by well-differentiated morphology and 21-55\% Ki-67 LI; NEC G3 that are poorly differentiated and show 21-55\% Ki-67 LI and finally NEC G4 that are poorly differentiated and show Ki-67 LI >55\% (Fazio \& Milione 2016). The new classification of pancreatic NEN (Klöppel et al. 2017) has partially upheld this proposal: indeed, the G3 category now includes not only poorly differentiated forms (NEC G3), but also well-differentiated ones (NET G3). These observations have been supported by molecular findings (Girardi et al. 2017), but they are still a matter of great debate. Indeed, the proposal to discriminate G3 from

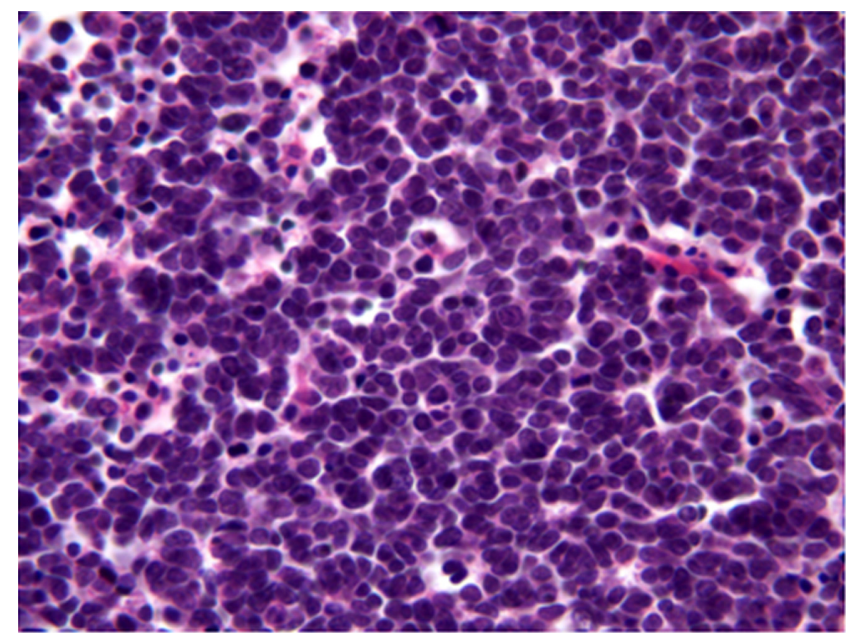

Figure 1

A case of small-cell carcinoma consisting of a dense proliferation of small-sized cells with high nucleus/cytoplasm ratio, nuclear moulding, without prominent nucleoli. (Hematoxylin and eosin stain, 40x magnification.)

G4 NEC only on the basis of Ki67, considering 55\% as cutoff, is supported by the evidence provided by a large clinical study (Sorbye et al. 2013) but has not been adopted by any consensus group. Therefore, there are open questions that still need to be clarified.

\section{What is meant by 'differentiation'?}

A general rule is that the more the neoplasm recapitulates the normal tissue, the more it can be considered as well differentiated. In other sites, specific histological

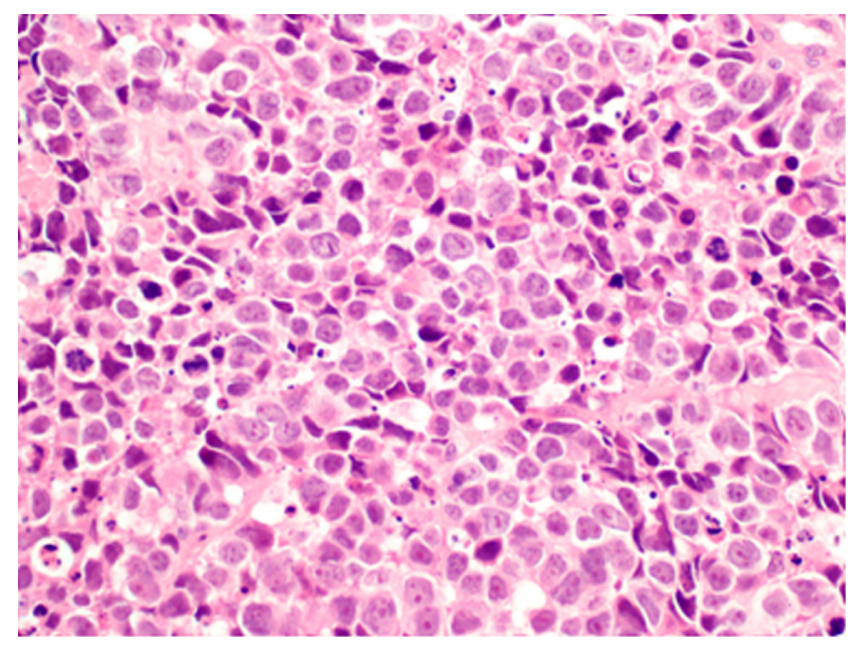

Figure 2

A case of large-cell neuroendocrine carcinoma: large-sized cells with abundant cytoplasm and nuclei with vesicular chromatin and a central nucleolus are typical morphologic features of this NEC subtype. (Hematoxylin and eosin stain, 40x magnification.)
C) 2018 Society for Endocrinology Published by Bioscientifica Ltd. Printed in Great Britain 


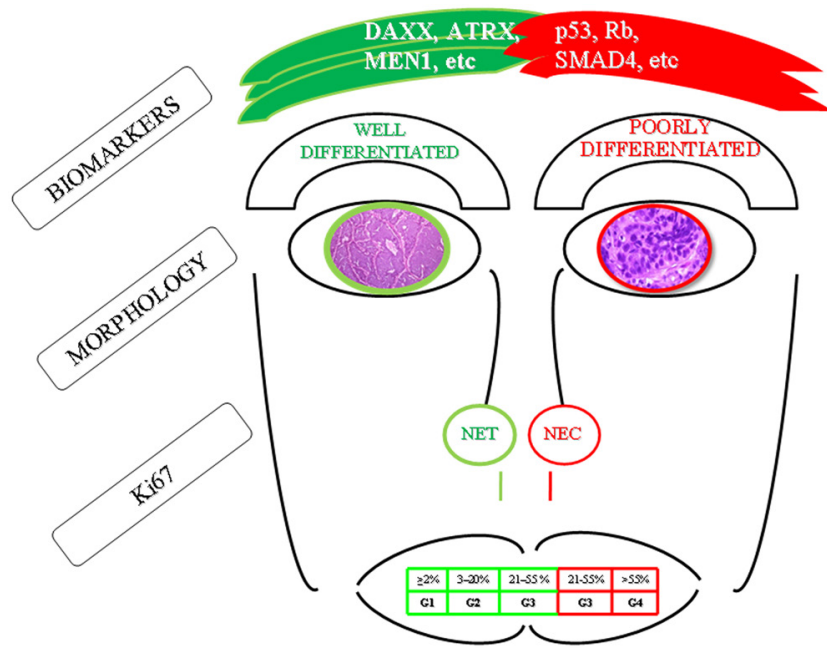

Figure 3

Schematic representation of the new proposed diagnostic algorithm for GEP-neuroendocrine neoplasms that is mainly based on the combination of morphology and Ki-67 labeling Index. In some instances, especially in pancreatic NEN, an integration with immunohistochemical and molecular study of additional biomarkers is needed.

grading scores have been applied for years and have proved to be of great clinical value. Concerning NEN, there is compelling need to make the morphological interpretation of the histological grade homogeneous and reproducible, which is a difficult task to be realized due to their potential ubiquitous localization. Within the same histological grade, morphological features characterizing these tumors are not completely overlapping in all sites. As an example, many site-specific features may be observed in the whole gastrointestinal tract. In the past, an attempt of classification was based on the embryonic origin: foregut tumors are those deriving from thymus, esophagus, lung, stomach, pancreas, gallbladder and duodenum; midgut tumors derive from appendix, ileum, caecum and ascending colon and finally hindgut tumors from distal large bowel and rectum. In the past, welldifferentiated tumors (Soga \& Tazawa 1971) were divided, on the basis of histological architectural patterns, into type A (insular solid; more common in the small bowel and appendix), type B (trabecular or ribbon-like; in the rectum or sigmoid colon) and type $\mathrm{C}$ (glandular; in the ampullary region). Although this division is no longer in use, such a morphological variability is common to both well-differentiated neoplasms and poorly differentiated large-cell carcinomas, mainly concerning cytological features (Fazio \& Milione 2016). This morphological diagnostic algorithm, combined with Ki-67 LI evaluation, discriminates well-differentiated high-grade neoplasms (G3 NET) from neuroendocrine carcinoma (G3 NEC) in the gastrointestinal tract (Fig. 3). However, the evaluation of the described features might depend on the operator, especially in the absence of a specific pathology training (Milione \& Fazio 2017) or on tumor sampling.

Furthermore, in a large proportion of high-grade NEN of the pancreas, it was shown that additional ancillary information, including clinical findings and biomarker expression, may be of aid in the distinction of NET G3 from NEC G3 to 4 (Basturk et al. 2014, Tang et al. 2016b). Therefore, in pancreatic NEN, molecular information needs to be included in the diagnostic algorithm (Fig. 3).

\section{Are G3 NEN homogeneous?}

Five studies (Vélayoudom-Céphise et al. 2013, Basturk et al. 2015, Heetfeld et al. 2015, Tang et al. 2016a, Milione et al. 2017) investigated the role of morphology in G3 NENs, mostly of the gastrointestinal tract. All of them provide data supporting the evidence that the current WHO G3 category is heterogeneous, containing at least two different groups of tumors. On a total of 461 analyzed cases (Table 1), G3 NETs were more often observed in the pancreas, representing 43\% of G3 pancreatic NENs. The second most common site of this new category is the ileum (35\% of ileal G3 NENs) and then the stomach (18\%). Therefore, most of the knowledge concerning G3 NETs originates from the pancreatic site. Moreover, in this context, G3 NEC represents a peculiar entity, accurate diagnosis of which is not straightforward, because of the wide range of differential diagnoses to be taken into consideration (G3 NET, acinar cell carcinoma, mixed acinar-NEC and primitive neuroectodermal tumor) (Basturk et al. 2014). Site-specific distribution of high- and low-grade NEN throughout the gastrointestinal tract may be explained by the different histological conformation of various districts. In the esophagus, for example, well-differentiated NETs are uncommon, probably because normal tissue does not contain a significant neuroendocrine population (Odze \& Goldblum 2015). Interestingly, in one of the five case series that studied G3 NEN (Milione et al. 2017), it was observed that midgut and/or hindgut sites of origin statistically correlated with a worse survival as compared with foregut. Given the heterogeneity of G3 NEN, much has yet to be clarified as concerns differential diagnosis and sub-categorization into G3 NET and G3 NEC in the various tumor sites of origin. On top of these difficulties lays the well-known intra-tumoral NEN heterogeneity. Indeed, these neoplasms may display areas characterized by high grade with foci showing low/intermediate grade, especially in the settings 
Table 1 Studies evaluating site-specific distribution of G3 NEN, with detail of G3 NET.

\begin{tabular}{lc}
\hline Site & G3 NEN \\
\hline Esophagus & $8^{\mathrm{d}}+5^{\mathrm{e}}$ \\
Stomach & $17^{\mathrm{d}}+28^{\mathrm{e}}$ \\
Pancreas & $9^{\mathrm{a}}+62^{\mathrm{b}}+21^{\mathrm{c}}+65^{\mathrm{d}}+33^{\mathrm{e}}$ \\
Duodenum & $7^{\mathrm{d}}+5^{\mathrm{e}}$ \\
lleum & $6^{\mathrm{c}}+11^{\mathrm{d}}+17^{\mathrm{e}, *}$ \\
Colon & $31^{\mathrm{d}}+46^{\mathrm{e}}$ \\
Biliary ducts & $2^{\mathrm{c}}+2^{\mathrm{e}}$ \\
Rectum & $2^{\mathrm{c}}+24^{\mathrm{d}}+1 \mathrm{1}$ \\
Lung & $2^{\mathrm{a}}$ \\
Thymus & $2^{\mathrm{a}}$ \\
Larynx & $3^{\mathrm{a}}$ \\
Unknown & $7^{\mathrm{a}}+28^{\mathrm{d}}$ \\
Others & $4^{\mathrm{a}}+13^{\mathrm{d}}$ \\
\hline
\end{tabular}

$\begin{array}{r}\hline \text { Total } \\ \hline 13 \\ 45 \\ 190 \\ 12 \\ 34 \\ 77 \\ 4 \\ 27 \\ 2 \\ 2 \\ 3 \\ 35 \\ 17 \\ \hline\end{array}$

\begin{tabular}{c} 
G3 NET \\
$0^{d}+0^{e}$ \\
$3^{d}+5^{e}$ \\
$7^{a}+1^{b}+21^{c}+24^{d}+11 e$ \\
$1^{d}+0^{e}$ \\
$6^{c}+2^{d}+4^{e}$ \\
$0^{d}+4^{e}$ \\
$2^{c}+0^{e}$ \\
$2^{c}+3^{d}+0^{a}$ \\
$1^{a}$ \\
$2^{a}$ \\
$1^{a}$ \\
$1^{a}+0^{d}$ \\
$0^{a}+1^{d}$ \\
\hline
\end{tabular}

Total (\%)

*lleum + cecum + appendix; aVélayoudom-Céphise et al. (2013); bBasturk et al. (2015); cTang et al. (2016a,b); dHeetfeld et al. (2015); eMilione et al. (2017). n.e., not evaluable.

of a well-differentiated NET G1-2 progressing to a NET G3 (Tang et al. 2016a). Therefore, the correct characterization of G3 NEN remains a matter of great debate.

\section{Staging system: what staging for G3 NET?}

According to the European Neuroendocrine Tumor Society, all NENs are classified in a single system (Rindi et al. 2006). The American Joint Committee on Cancer (AJCC), on the other hand, in the seventh (Edge et al. 2010) and in the eighth edition (Asare et al. 2017), applies this system only to G1 and G2 NETs. Concerning G3 NEC, the AJCC recommends to classify them according to the TNM staging of adenocarcinomas of the site of origin (Edge et al. 2010, Asare et al. 2017). G3 NETs are still in a grey zone since they represent 'high-grade, well-differentiated forms', whose biological behavior is quite similar to G2 NET in the first 2 years from diagnosis in terms of overall survival (OS) (Milione et al. 2017). Indeed, the AJCC suggests to use the parameters of well-differentiated forms in staging the rare G3 NET, rather than those of poorly differentiated carcinomas (Asare et al. 2017).

\section{Lung and thorax 'G3' NEN: more morphology, less proliferation!}

The current WHO Classification of lung and thorax NEN (Brambilla et al. 2015) catalogues four categories on the basis of morphological parameters (well-differentiated/ high-grade neoplasm, absence/presence of necrosis and mitotic activity): typical carcinoid; atypical carcinoid; large-cell neuroendocrine carcinoma (LCNEC); smallcell lung carcinoma (SCLC). No role is recognized for Ki-67 LI, while, unlike GEP NEN, in this classification, morphology alone plays an essential role. Attempts to introduce a three-tiered grading based on Ki-67 LI, together with mitotic count and necrosis, were performed, but no clinical utility was achieved before the approval of the last classification. A new proposal for a diagnostic algorithm is emerging for lung NEN that is, just as for the GEP district, an integration of morphology (necrosis and mitoses) and proliferation (Ki-67 LI), aimed at identifying three NEN categories: Lu-NET G1, Lu-NET G2 and Lu-NET G3 (Rindi et al. 2013). This proposal would allow to handle tumors with similar behavior according to their own biological potential. Furthermore, it would be worth to consider the mitotic count among the diagnostic criteria. Indeed, NET G3 are often diagnosed only on the basis of Ki-67 LI, but a low mitotic count ( $<20$ mitosis/10 HPF) in a case with elevated Ki-67 LI (>20\%) could be helpful in identifying a well-differentiated form of high-grade NEN.

\section{Molecular characteristics}

A recently published comprehensive genomic analysis of 102 clinically sporadic pancreatic NETs disclosed the presence of genetic alterations affecting DNA damage and repair, chromatin remodeling, telomere maintenance and mammalian target of rapamycin (mTOR) signaling (Scarpa et al. 2017), providing a significant contribution to the understanding of this disease and helping in risk stratification and treatment. However, only $5 \%$ of the investigated pancreatic NETs were G3, and there is no specification as to whether they were well- or poorly differentiated neoplasms. Therefore, this study cannot help in differentiating G3 NEN in the proposed subcategories. Conversely, in the field of NEN, most of the 
detected molecular alterations involve NECs. Mutations in TP53, BRAF or RAS genes, aberrations in the p16/ $\mathrm{Rb} /$ cyclin D1 signaling pathway and microsatellite instability are the most frequently reported molecular derangements (Pizzi et al. 2003, Kimiloglu Sahan et al. 2015, Vijayvergia et al. 2016). These features are often shared by both adenocarcinomas and NEC components of mixed adenoneuroendocrine carcinomas, as it was shown mostly in cases of colorectal NEC (Takizawa et al. 2015, Woischke et al. 2017), and almost never detected in NET (Takizawa et al. 2015). These proofs strongly suggest that NECs and NETs belong to two different families, linked by some histologic overlap and expression of neuroendocrine markers, but differing substantially in terms of their genomic bases, clinical presentation and relationship to non-NE neoplasms. In addition, a recent retrospective study found that pancreatic G3 NET display DAXX, ATRX and MEN1 gene mutations, similarly to well-differentiated G2 NET, and not RB1 or TP53 gene mutations, commonly found in G3 NEC (Hijioka et al. 2015, Tang et al. 2016a,b). Therefore, the characterization of such molecular derangements may help in differentiating G3 NET from G3 NEC when morphology is not sufficient (Tang et al. 2016b, Konukiewitz et al. 2017). Along this line, in pancreatic NET loss-of-function mutations in DAXX and ATRX genes have been described, with consequent loss of expression of their related proteins by immunohistochemistry (Yachida et al. 2012). Inactivating mutations of these genes were exclusive of this form, since they have not been detected either in small-cell or in large-cell NEC. This finding could suggest that well-differentiated NETs are genetically distinct from poorly differentiated forms. In the thoracic district, comparative genomic hybridization studies and gene-expression profiling data have shown that carcinoids are biologically different from NECs of the lung (Swarts et al. 2012), and may help in further characterizing lung NENs. Despite these promising results, the applied methodology is not widely available and validation studies are still lacking. In a large series of LCNECs (Rekhtman et al. 2016), three tumor subsets were identified on the basis of their genomic signatures: a major group, characterized by TP53 $+R B 1$ co-mutation/loss and other SCLC-type alterations (e.g. MYCL amplification), another major group with NSCLC-like genetic profile, characterized by the lack of co-altered TP53 $+R B 1$ and the occurrence of NSCLC-type mutations (STK11, KRAS, KEAP1) and, finally, a minor group, carcinoid-like, characterized by MEN1 mutations and low mutation burden.
Another open issue concerns the role of immunocheckpoints in NEN. Recently, programmed death-ligand 1 (PD-L1) expression was assessed in 32 GEP NET (Kim et al. 2016), where it was found to associate with progression-free survival (PFS) and OS. Others found PD-L1 to be expressed only in high-grade forms (Li et al. 2016). In the lung, PD-L1 expression was apparent in $10.4 \%$ of LCNECs and $5.8 \%$ of SCLCs and was not observed in carcinoid tumors (Tsuruoka et al. 2017), therefore suggesting that PD-L1 staining might help in differentiating poorly from well-differentiated lung NETs.

\section{Does microenvironment have a role in NENs?}

It is not clear why tumors arising in different tissues have different metastasizing behavior. Tumor progression depends on complex biochemical and biological changes occurring in cancer cells and in the associated stroma. In addition, the immune system has a critical role providing defense actions and attack mechanisms against cancer (Weinberg 2014). The existence of an interconnection between the neuroendocrine system and the microenvironment has been studied for years. Chromogranin A, one of the major circulating NEN markers, is believed to be able to influence neoplastic stroma and tumor growth (Corti et al. 2010, Marotta et al. 2018). Moreover, neuroendocrine mediators are able to enhance inflammatory states and to interfere with the immune response (Zappalà et al. 2013). In addition, the issue of epigenetic influence on metastatic behavior of low-to-intermediate grade NEN, rather than a genetic drive, is still open. Heterogeneity in the epigenetic profiles of different primary sites has been shown in NEN, thus suggesting the presence of underlying differences in tumorigenic processes, microenvironment-driven modulation of epigenetic states and/or their possible correlation with the biological aggressiveness of these diverse neoplasms (Cives et al. 2016). The clinical influence of this finding is under investigation: the definition of an epigenetic fingerprinting could provide a more successful prognostic stratification than those based on grade, site and differentiation.

\section{Management}

In non-metastatic NET G3, surgery appears as the first option, but, at the same time, the least frequent; therefore, systemic therapy is often necessary. Generally, chemotherapy regimen in pancreatic NET G3 is similar to 
that implemented in NET G1/2 when Ki-67 LI is $<55 \%$, while it is similar to the NEC chemotherapy regimen when Ki-67 LI is $>55 \%$. Literature reports describe many different medical treatments for these tumors, ranging from somatostatin analogs (SSAs), to platinum-based regimens and molecular targeted drugs.

As concerns NET G3, a study evaluating 30 patients mostly affected with GEP tumors demonstrated the efficacy of SSAs in obtaining disease control (considered as stable disease and partial/complete response) in $70 \%$ of the cases (Aparicio et al. 2001). A further study employed SSA in combination with fluorouracil (5-FU) in 29 GEP NET G3 patients, showing disease control in $93 \%$ of the cases (Brizzi et al. 2009). On the other hand, in studies employing chemotherapy including variable regimens (5-FU, streptozotocin, platinum-based drugs alone or in combination with etoposide, capecitabine and/or vincristine) disease control was achieved in $~ 50 \%$ of the patients (Moertel et al. 1991, Mitry et al. 1999, Bajetta et al. 2007, Turner et al. 2010).

As concerns NEC G3, a study employing SSA showed disease control in only one patient out of the five treated (Aparicio et al. 2001). Two studies including 464 bronchopulmonary NECs (Mavroudis et al. 2001, Hanna et al. 2006) showed a very limited efficacy of the diverse chemotherapeutic regimens employed (platinumbased drugs alone or in combination with etoposide, irinotecan or paclitaxel), with disease control limited to $36 \%$ of the patients. As for GEP-NEC G3, 9 studies employed chemotherapy including 386 patients treated with variable regimens (5-FU, streptozotocin, platinumbased drugs alone or in combination with etoposide, capecitabine and/or vincristine), showing disease control in $\sim 65 \%$ of the patients (Moertel et al. 1991, Mitry et al. 1999, Brenner et al. 2004, Hainsworth et al. 2006, Bajetta et al. 2007, Iwasa et al. 2010, Turner et al. 2010, Welin et al. 2011).

Therefore, these studies support the hypothesis that NET G3 may be managed by SSA, in association or not with chemotherapy, obtaining an overall good disease control rate. On the contrary, NEC G3 seems to respond better to chemotherapy, mostly platinum-based compounds in combination with different other drugs. Conversely, bronchopulmonary NECs display a lower sensitivity to chemotherapy as compared to NEC of GEP origin. Platinum-based chemotherapy appears to be better than other types of chemotherapy for LCNEC, although there are no randomized studies indicating that platinum is the treatment of choice for these tumors. Thang and coworkers explored peptide receptor radionuclide therapy (PRRT) efficacy in G3 NEN, evaluated by response evaluation criteria in solid tumors (RECIST) 1.1 criteria and toxicity (Thang et al. 2018). They observed a longer PFS (12 months) and OS (46 months) in 22 patients with $\mathrm{Ki}-67 \mathrm{LI} \leq 55 \%$ as compared to 6 patients with Ki-67 LI $>55 \%$ (4 and 7 months, respectively). Patients with FDG-avid disease, likely less differentiated, showed progression, but clinically significant response (partial response + disease stabilization) was obtained in $74 \%$ of the other 23 patients. Therefore, even though evidence is not very strong, PRRT may be considered as a potential therapeutic strategy also for G3 NEN. It should be underlined, however, that only few of the evaluated studies were performed by dividing G3 NEN on the basis of the new concepts of differentiation. Available literature was analyzed by dissecting the studies and taking into consideration those reporting grade and differentiation, trying to draw conclusions that, of course, cannot provide solid information, but only general indications. Only prospective studies will provide definitive information concerning the most appropriate therapeutic regimen for NET G3 and for NEC G3.

\section{Prognosis}

In keeping with the evidence that one of the main prognostic markers in NEN is represented by cell differentiation (Madeira et al. 1998, Faggiano et al. 2007), NET G3 displays less aggressive features as compared to NEC G3 but worse outcome as compared to NET G2, with a disease-specific survival ranging from 41 to 55 months (Vélayoudom-Céphise et al. 2013, Sorbye et al. 2014, Basturk et al. 2015, Crippa et al. 2016a). A recent study retrospectively evaluating 136 G3 GEP-NEC patients with a median follow-up of 81 months, showed an independent prognostic value for Ki-67 LI, mismatch repair proteins, stage and CD117 expression (Milione et al. 2017). The authors provided support for a sub-classification of G3 NEN in three 'types', on the basis of morphology and Ki-67 LI, which are associated with different prognosis. They indeed identified: type A neoplasms, represented by well-differentiated tumors with a Ki-67 LI $=20-55 \%$ and median OS of 43.6 months; type $\mathrm{B}$, represented by poorly differentiated neoplasms with a Ki-67 LI $=20-55 \%$ and median OS of 24.5 months; type $\mathrm{C}$, represented by poorly differentiated neoplasms with a Ki-67 LI $\geq 55 \%$ and median OS of 5.3 months. In addition, NET G3 may include patients with welldifferentiated NET showing $<20$ mitoses/10 HPF 


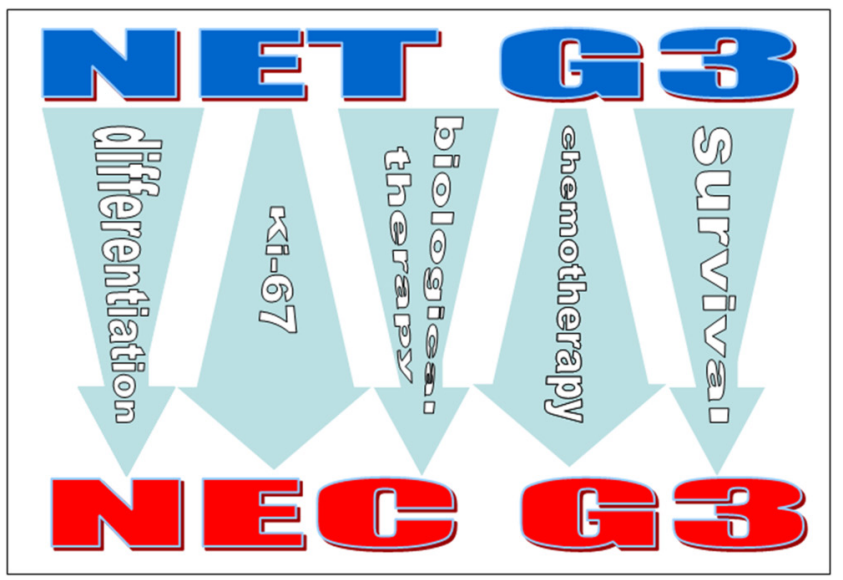

Figure 4

The different spectrum of G3: NET to NEC.

(G2 by mitotic count) but Ki-67 LI $>20 \%$. These gradediscordant NETs have been shown to display a worse prognosis as compared to grade-concordant G2 NETs (54 vs 68 months) (Basturk et al. 2014). In keeping with the bad prognosis of poorly differentiated cancers, NEC G3 represents a group of very aggressive neoplasms. Pancreatic NEC G3 behaves similar to SCLC: they display lymph node and distant metastases since diagnosis and are associated with a median survival of $\sim 1$ year (Basturk et al. 2014, Crippa et al. 2016b). Most of these patients may die few weeks after diagnosis, even if treated with

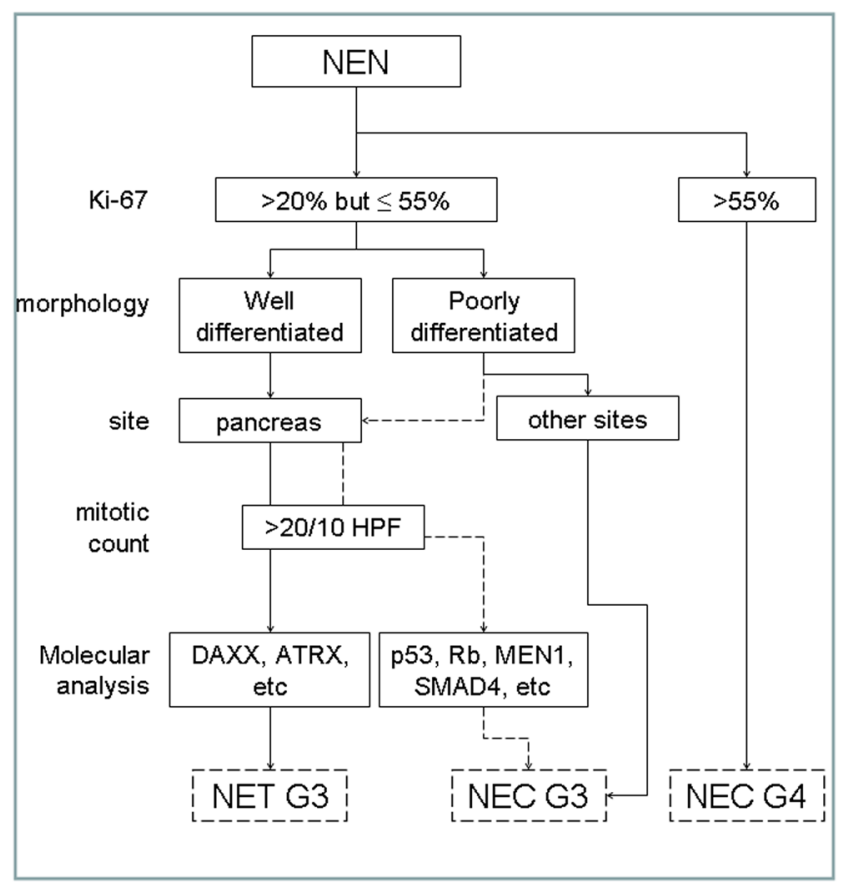

Figure 5

Indicative flow-chart for NEN G3 diagnosis.

http://erc.endocrinology-journals.org https://doi.org/10.1530/ERC-17-0507 aggressive systemic chemotherapy (Sorbye et al. 2013) . Therefore, it is apparent that still a lot of work has to be done in order to better characterize these tumors and provide clinically useful information, especially for treatment purposes.

\section{Conclusions}

The available studies highlight the rapid evolution in defining and characterizing NEN categories on the basis of the growing amount of evidence in this field. G3 NEN diagnostic criteria need to be refined in order to better address treatment on the basis of differential outcomes of these tumors. Going back to highlight the importance of morphological differentiation may represent an important indication in the difficult management of these tumors (Fig. 4). It is indeed crucial to gather as much information as possible in order to ensure the best and quickest diagnostic path to these patients, that need to be promptly (and frequently aggressively) treated (Fig. 5).

Only prospective studies will allow us to respond to the several questions raised by our analysis.

\section{Declaration of interest}

M C Zatelli has received consultant fees from Novartis, Pfizer and Genzyme. The other authors declare that there is no conflict of interest that could be perceived as prejudicing the impartiality of this review.

\section{Funding}

This work was supported by grants from the Italian Ministry of Education, Research and University (FIRB RBAP11884 M, RBAP1153LS); Associazione Italiana per la Ricerca sul Cancro in collaboration with 'Laboratorio in rete del Tecnopolo Tecnologie delle Terapie Avanzate' of the University of Ferrara. This review is part of the 'Neuroendocrine Tumors Innovation Knowledge and Education' project led by Prof. Annamaria Colao, which aims at increasing the knowledge on NET.

\section{Author contribution statement}

Maria Chiara Zatelli wrote the Abstract, the Introduction, the Aim and Methodology, the part related to Management and Prognosis, the Conclusions and revised the manuscript; Elia Guadagno: wrote the part related to Diagnosis; Erika Messina helped in analyzing the literature on treatment of G3 NET/NEC and corrected the references; Fabio Lo Calzo helped in analyzing the literature on treatment of G3 NET/NEC and provided a critical review; Antongiulio Faggiano proof-read the manuscript; Annamaria Colao supervised the project.

\section{Acknowledgements}

The authors deeply thank Dr Massimo Milione (Istituto Nazionale Tumori, Milano) for the critical evaluation of the manuscript, the contribution in the pathological review and for providing the pathological pictures in Fig. 3. They would also like to acknowledge all the collaborators of 
this project: Albertelli M (Genova), Bianchi A (Roma), Circelli L (Napoli), De Cicco F (Napoli), Dicitore A (Milano), Di Dato C (Roma), Di Molfetta S (Bari), Fanciulli G (Sassari), Ferraù F (Messina), Gallo M (Torino), Giannetta E (Roma), Grillo F (Genova), Grossrubatscher E (Milano), Guarnotta V (Palermo), Isidori A M (Roma), Kara E (Udine), Malandrino P (Catania), Modica R (Napoli), Muscogiuri G (Napoli), Pizza G (Napoli), Razzore P (Torino), Rota F (Roma), Rubino M (Milano), Ruggeri R M (Messina), Sciammarella C (Napoli), Vitale G (Milano).

\section{References}

Asare E, Bergsland EK, Brierley J, Bushnell D, Jensen R, Kim M, Klimstra D, Liu E, Nakakura E, O'Dorisio T, et al. 2017 Neuroendocrine tumors. In AJCC Cancer Staging Manual, 8th ed., pp 351-419. Chicago, IL, USA: American Joint Committee on Cancer.

Aparicio T, Ducreaux M, Baudin E, Sabourin JC, De Baere T, Mitry E, Schlumberger M \& Rougier P 2001 Antitumor activity of somatostatin analogues in progressive metastatic neuroendocrine tumors. European Journal of Cancer 37 1014-1019. (https://doi. org/10.1016/S0959-8049(01)00073-9)

Bajetta E, Catena L, Procopio G, De Dosso S, Bichisao E, Ferrari L, Martinetti A, Platania M, Verzoni E, Formisano B \& Bajetta R 2007 Are capecitabine and oxaliplatin (XELOX) suitable treatments for progressing low-grade and high-grade neuroendocrine tumours? Cancer Chemotherapy and Pharmacology 59 637-642. (https://doi. org/10.1007/s00280-006-0306-6)

Basturk O, Tang L, Hruban RH, Adsay V, Yang Z, Krasinskas AM, Vakiani E, LaRosa S, Jang KT, Frankel WL, et al. 2014 Poorly differentiated neuroendocrine carcinomas of the pancreas: a clinicopathologic analysis of 44 cases. American Journal of Surgical Pathology 38 437-447. (https://doi.org/10.1097/ PAS.0000000000000169)

Basturk O, Yang Z, Tang LH, Hruban RH, Adsay V, McCall CM, Krasinskas AM, Jang KT, Frankel WL, Balci S, et al. 2015 The highgrade (WHO G3) pancreatic neuroendocrine tumor category is morphologically and biologically heterogenous and includes both well differentiated and poorly differentiated neoplasms. American Journal of Surgical Pathology 39 683-690. (https://doi.org/10.1097/ PAS.0000000000000408)

Brambilla E, Beasley MB, Austin AHM, Capelozzi VL, Chirieac LR, Devesa SS, Frank GA, Gazdar A, Ishikawa Y, Jen J, et al. 2015 Neuroendocrine tumors. In WHO Classification of Tumours of the Lung, Pleura, Thymus and Heart. Eds WD Travis, E Brambilla, AP Burke, A Marx \& AG Nicholson. Lyon, France: IARC Press.

Brenner B, Shah MA, Gonen M, Klimstra DS, Shia J \& Kelsen DP 2004 Small-cell carcinoma of the gastrointestinal tract: a retrospective study of 64 cases. British Journal of Cancer 90 1720-1726. (https:// doi.org/10.1038/sj.bjc.6601758)

Brizzi MP, Berruti A, Ferrero A, Milanesi E, Volante M, Castiglione F, Birocco N, Bombaci S, Perroni D, Ferretti B, et al. 2009 Continuous 5-fluorouracil infusion plus long acting octreotide in advanced welldifferentiated neuroendocrine carcinomas. A phase II trial of the Piemonte oncology network. BMC Cancer 9 388. (https://doi. org/10.1186/1471-2407-9-388)

Chan DL, Ferone D, Albertelli M, Pavlakis N, Segelov E \& Singh S 2017 a Escalated-dose somatostatin analogues for antiproliferative effect in GEPNETS: a systematic review. Endocrine 57 366-375. (https://doi. org/10.1007/s12020-017-1360-z)

Chan DL, Segelov E \& Singh S $2017 b$ Everolimus in the management of metastatic neuroendocrine tumours. Therapeutic Advances in Gastroenterology 10 132-141. (https://doi.org/10.1177/17562 $83 \times 16674660)$

Cives M \& Strosberg J 2017 Treatment strategies for metastatic neuroendocrine tumors of the gastrointestinal tract. Current
Treatment Options in Oncology 18 14. (https://doi.org/10.1007/s11864017-0461-5)

Cives M, Simone V, Rizzo FM \& Silvestris F 2016 NETs: organ related epigenetic derangements and potential clinical applications. Oncotarget 7 57414-57429. (https://doi.org/10.18632/ oncotarget.10598)

Corti A 2010 Chromogranin A and the tumor microenvironment. Cellular and Molecular Neurobiology 30 1163-1170. (https://doi. org/10.1007/s10571-010-9587-8)

Crippa S, Partelli S, Bassi C, Berardi R, Capelli P, Scarpa A, Zamboni G \& Falconi M 2016a Long-term outcomes and prognostic factors in neuroendocrine carcinomas of the pancreas: morphology matters. Surgery 159 862-871. (https://doi.org/10.1016/j.surg.2015.09.012)

Crippa S, Partelli S, Belfiori G, Palucci M, Muffatti F, Adamenko O, Cardinali L, Doglioni C, Zamboni G \& Falconi M $2016 b$ Management of neuroendocrine carcinomas of the pancreas (WHO G3): a tailored approach between proliferation and morphology. World Journal of Gastroenterology 22 9944-9953. (https://doi. org/10.3748/wjg.v22.i45.9944)

Edge S, Byrd DR, Compton CC, Fritz AG, Greene F \& Trotti A 2010 AJCC Cancer Staging Manual, 7th ed. New York, NY, USA: Springer-Verlag.

Faggiano A, Sabourin JC, Ducreux M, Lumbroso J, Duvillard P, Leboulleux S, Dromain C, Colao A, Schlumberger M \& Baudin E 2007 Pulmonary and extrapulmonary poorly differentiated large cell neuroendocrine carcinomas: diagnostic and prognostic features. Cancer 110 265-274. (doi. 10.1002/cncr.22791)

Fazio N \& Milione M 2016 Heterogeneity of grade 3 gastroenteropancreatic neuroendocrine carcinomas: new insights and treatment implications. Cancer Treatment Reviews 50 61-67. (https:// doi.org/10.1016/j.ctrv.2016.08.006)

Finkelstein P, Sharma R, Picado O, Gadde R, Stuart H, Ripat C, Livingstone AS, Sleeman D, Merchant N \& Yakoub D 2017 Pancreatic neuroendocrine tumors (panNETs): analysis of overall survival of nonsurgical management versus surgical resection. Journal of Gastrointestinal Surgery 21 855-866. (https://doi.org/10.1007/s11605017-3365-6)

Gallo M, Malandrino P, Fanciulli G, Rota F, Faggiano A, Colao A \& NIKE Group 2017 Everolimus as first line therapy for pancreatic neuroendocrine tumours: current knowledge and future perspectives. Journal of Cancer Research and Clinical Oncology 143 1209-1224. (https://doi.org/10.1007/s00432-017-2407-5)

Girardi DM, Silva ACB, Rêgo JFM, Coudry RA \& Riechelmann RP 2017 Unraveling molecular pathways of poorly differentiated neuroendocrine carcinomas of the gastroenteropancreatic system: a systematic review. Cancer Treatment Reviews 56 28-35. (https://doi. org/10.1016/j.ctrv.2017.04.002)

Hainsworth JD, Spigel DL, Litchy S \& Greco A 2006 Phase II trial of paclitaxel, carboplatin, and etoposide in advanced poorly differentiated neuroendocrine carcinoma: a Minnie Pearl Cancer Research Network Study. Journal of Clinical Oncology 24 3548-3554. (10.1200/JCO.2005.05.0575)

Hanna N, Bunn PA Jr, Langer C, Einhorn L, Guthrie T Jr, Beck T, Ansari R, Ellis P, Byrne M, Morrison M, et al. 2006 Randomized phase III trial comparing irinotecan/cisplatin with etoposide/ cisplatin in patients with previously untreated extensive-stage disease small-cell lung cancer. Journal of Clinical Oncology 24 2038-2943. (https://doi.org/10.1200/JCO.2005.04.8595)

Heetfeld M, Chougnet CN, Olsen IH, Rinke A, Borbath I, Crespo G, Barriuso J, Pavel M, O'Toole D \& Walter T 2015 Characteristics and treatment of patients with G3 gastroentero pancreatic neuroendocrine neoplasms. Endocrine-Related Cancer 22 657-664. (https://doi.org/10.1530/ERC-15-0119)

Hijioka S, Hosoda W, Mizuno N, Hara K, Imaoka H, Bhatia V, Mekky MA, Tajika M, Tanaka T, Ishihara M, et al. 2015 Does the WHO 2010 classification of pancreatic neuroendocrine neoplasms accurately characterize pancreatic neuroendocrine carcinomas?
(2) 2018 Society for Endocrinology Published by Bioscientifica Ltd. Printed in Great Britain 
Journal of Gastroenterology 50 564-572. (https://doi.org/10.1007/ s00535-014-0987-2.50)

Hilal T 2017 Current understanding and approach to well differentiated lung neuroendocrine tumors: an update on classification and management. Therapeutic Advances in Medical Oncology 9 189-199. (https://doi.org/10.1177/1758834016678149)

Iwasa S, Morizane C, Okusaka T, Ueno H, Ikeda M, Kondo S, Tanaka T, Nakachi K, Mitsunaga S, Kojima Y, et al. 2010 Cisplatin and etoposide as first-line chemotherapy for poorly differentiated neuroendocrine carcinoma of the hepatobiliary tract and pancreas. Japanese Journal of Clinical Oncology 40 313-318. (https://doi.org/10.1093/jico/hyp173)

Kim ST, Ha SY, Lee S, Ahn S, Lee J, Park SH, Park JO, Lim HY, Kang WK, Kim KM \& Park YS 2016 The impact of PD-L1 expression in patients with metastatic GEP-NETs. Journal of Cancer 7 484-489. (https://doi. org/10.7150/jca.13711)

Kimiloglu Sahan E, Erdogan N, Ulusoy I, Samet E, AkyıldızĬğdem A \& Gönüllü D. 2015 P53, KI-67, CD117 expression in gastrointestinal and pancreatic neuroendocrine tumours and evaluation of their correlation with clinicopathological and prognostic parameters. Turkish Journal of Gastroenterology 26 104-111. (https://doi. org/10.5152/tjg.2015.1965)

Klöppel G, Couvelard A, Hruban RH, Klimstra DS, Komminoth P, Osamura RY, Perren A \& Rindi G 2017 WHO classification of neoplasms of the neuroendocrine pancreas. In WHO Classification of Tumors of Endocrine Organs. Eds RV Lloyd, RY Osamura, G Klöppel \& J Rosai. Lyon, France: IARC Press.

Konukiewitz B, Schlitter AM, Jesinghaus M, Pfister D, Steiger K, Segler A, Agaimy A, Sipos B, Zamboni G, Weichert W, et al. 2017 Somatostatin receptor expression related to TP53 and RB1 alterations in pancreatic and extrapancreatic neuroendocrine neoplasms with a Ki67-index above 20. Modern Pathology 30 587-598. (https://doi.org/10.1038/ modpathol.2016.217)

Lambrescu I, Fica S, Martins D, Spada F, Cella C, Bertani E, Rubino M, Gibelli B, Grana C, Bonomo G, et al. 2017 Metronomic and metronomic-like therapies in neuroendocrine tumors - rationale and clinical perspectives. Cancer Treatment Reviews 55 46-56. (https://doi. org/10.1016/j.ctrv.2017.02.007)

Li Z, Leng J, Wang H, Li S, Lu M, Zhou L, Huang X, Jia L, Kang Q, Li J, et al. 2016 PD-L1 expression is associated with grade of neuroendocrine tumors. Abstracts of the 13th Annual ENETS Conference for the Diagnosis and Treatment of Neuroendocrine Tumor Disease, March 9-11, 2016, Barcelona, Spain. Neuroendocrinology 103 (Suppl 1) abstract G10 pp39. (https://doi.org/10.1159/000448725)

Madeira I, Terris B, Voss M, Denys A, Sauvanet A, Flejou JF, Vilgrain V, Belghiti J, Bernades P \& Ruszniewski P 1998 Prognostic factors in patients with endocrine tumours of the duodenopancreatic area. Gut 43 422-427. (https://doi.org/10.1136/gut.43.3.422)

Marotta V, Zatelli MC, Sciammarella C, Ambrosio MR, Bondanelli M, Colao A \& Faggiano A 2018 Chromogranin A as circulating marker for diagnosis and management of neuroendocrine neoplasms: more flaws than fame. Endocrine-Related Cancer 25 R11-R29. (https://doi org/10.1530/ERC-17-0269)

Mavroudis D, Papadakis E, Veslemes M, Tsiafaki X, Stavrakakis J, Kouroussis C, Kakolyris S, Bania E, Jordanoglou J, Agelidou M, et al. 2001 A multicenter randomized clinical trial comparing paclitaxelcisplatin-etoposide versus cisplatin-etoposide as firstline treatment in patients with small-cell lung cancer. Annals of Oncology 12 463-470. (https://doi.org/10.1023/A:1011131303391)

Michael M, Garcia-Carbonero R, Weber MM, Lombard-Bohas C, Toumpanakis C \& Hicks RJ 2017 The antiproliferative role of Lanreotide in controlling growth of neuroendocrine tumors: a systematic review. Oncologist 22 272-285. (https://doi.org/10.1634/ theoncologist.2016-0305)

Milione M \& Fazio N 2017 G3 GEP NENs category: are basic and clinical investigations well integrated? Endocrine 60 28-30. (https://doi. org/10.1007/s12020-017-1365-7)
Milione M, Maisonneuve P, Spada F, Pellegrinelli A, Spaggiari P, Albarello L, Pisa E, Barberis M, Vanoli A, Buzzoni R, et al. 2017 The clinicopathologic heterogeneity of Grade 3 gastroenteropancreatic neuroendocrine neoplasms: morphological differentiation and proliferation identify different prognostic categories. Neuroendocrinology 104 85-93.

Mitry E, Baudin E, Ducreaux M, Sabourin JC, Rufié P, Aparicio T, Aparicio T, Lasser P, Elias D, Duvillard P, et al. 1999 Treatment of poorly differentiated neuroendocrine tumours with etoposide and cisplatin. British Journal of Cancer 81 1351-1355.

Moertel CG, Kvols LK, O’Connel MJ \& Rubin J 1991 Treatment of neuroendocrine carcinomas with combined etoposide and cisplatin. Cancer 68 227-232.

Neychev V \& Kebebew E 2017 Management options for advanced low or intermediate grade gastroenteropancreatic neuroendocrine tumors: review of recent literature. International Journal of Surgical Oncology 2017 14. (https://doi.org/10.1155/2017/6424812)

Odze RD \& Goldblum JR 2015 Neuroendocrine tumors of the gastrointestinal and pancreatobiliary tracts. In Surgical Pathology of the GI Tract, Liver, Biliary Tract, and Pancreas, 3rd ed., p 813. Philadelphia, PA, USA: Elsevier Saunders.

Pizzi S, Azzoni C, Bassi D, Bottarelli L, Milione M \& Bordi C 2003 Genetic alterations in poorly differentiated endocrine carcinomas of the gastrointestinal tract. Cancer 98 1273-1282.

Rekhtman N, Pietanza MC, Hellmann MD, Naidoo J, Arora A, Won H, Halpenny DF, Wang H, Tian SK, Litvak AM, et al. 2016 Nextgeneration sequencing of pulmonary large cell neuroendocrine carcinoma reveals small cell carcinoma-like and non-small cell carcinoma-like subsets. Clinical Cancer Research 22 3618-3629. (https://doi.org/10.1158/1078-0432.CCR-15-2946)

Rindi G, Kloppel G, Alhman H, Caplin M, Couvelard A, de Herder WW, Erikssson B, Falchetti A, Falconi M, Komminoth P, et al. 2006 TNM staging of foregut (neuro) endocrine tumors: a consensus proposal including grading system. Virchows Archives 449 395-401. (https://doi.org/10.1007/s00428-006-0250-1)

Rindi G, Arnold R, Bosman FT, Capella C, Klimstra DS, Kloppel G Komminoth P \& Solcia E 2010 Nomenclature and classification of neuroendocrine neoplasms of the digestive system. In $\mathrm{WHO}$ Classification of Tumors of the Digestive System. Eds FT Bosman, F Carneiro, H Hruban \& ND Theise. Lyon, France: IARC Press.

Rindi G, Klersy C, Inzani F, Fellegara G, Ampollini L, Ardizzoni A, Campanini N, Carbognani P, De Pas TM, Galetta D, et al. 2013 Grading the neuroendocrine tumors of the lung: an evidence-based proposal. Endocrine-Related Cancer 21 1-16. (https://doi.org/10.1530/ERC-13-0246)

Rinke A \& Gress TM 2017 Neuroendocrine cancer, therapeutic strategies in G3 cancers. Digestion 95 109-114. (https://doi. org/10.1159/000454761)

Scarpa A, Chang DK, Nones K, Corbo V, Patch AM, Bailey P, Lawlor RT, Johns AL, Miller DK, Mafficini A, et al. 2017 Whole-genome landscape of pancreatic neuroendocrine tumours. Nature 543 65-71. (https://doi.org/10.1038/nature21063)

Soga J \& Tazawa K 1971 Pathologic analysis of carcinoids; histologic reevaluation of 62 cases. Cancer 28 990-998.

Sorbye H, Welin S, Langer SW, Vestermark LW, Holt N, Osterlund P, Dueland S, Hofsli E, Guren MG, Ohrling K, et al. 2013 Predictive and prognostic factors for treatment and survival in 305 patients with advanced gastrointestinal neuroendocrine carcinoma (WHO G3): the NORDIC NEC study. Annals of Oncology 24 152-160. (https://doi.org/10.1093/annonc/mds276)

Sorbye H, Strosberg J, Baudin E, Klimstra DS \& Yao JC 2014 Gastroenteropancreatic high-grade neuroendocrine carcinoma Cancer 120 2814-2823. (https://doi.org/10.1002/cncr.28721)

Swarts DR, Ramaekers FC \& Speel EJ 2012 Molecular and cellular biology of neuroendocrine lung tumors: evidence for separate biological entities. Biochimica et Biophysica Acta 1826 255-271. (https://doi. org/10.1016/j.bbcan.2012.05.001)
(2) 2018 Society for Endocrinology Published by Bioscientifica Ltd. Printed in Great Britain 
Takizawa N, Ohishi Y, Hirahashi M, Takahashi S, Nakamura K, Tanaka M, Oki E, Takayanagi R \& Oda Y 2015 Molecular characteristics of colorectal neuroendocrine carcinoma; similarities with adenocarcinoma rather than neuroendocrine tumor. Human Pathology 46 1890-1900. (https://doi.org/10.1016/j. humpath.2015.08.006)

Tang LH, Untch BR, Reidy DL, O’Reilly E, Dhall D, Jih L, Basturk O, Allen PJ \& Klimstra DS 2016a Well-differentiated neuroendocrine tumors with a morphologically apparent high-grade component: a pathway distinct from poorly differentiated neuroendocrine carcinomas. Clinical Cancer Research 22 1011-1017. (https://doi. org/10.1158/1078-0432.CCR-15-0548)

Tang LH, Basturk O, Sue JJ \& Klimstra DS $2016 b$ A practical approach to the classification of WHO Grade 3 (G3) Well-differentiated Neuroendocrine Tumor (WD-NET) and Poorly Differentiated Neuroendocrine Carcinoma (PD-NEC) of the pancreas. American Journal of Surgical Pathology 40 1192-202. (https://doi.org/10.1097/ PAS.0000000000000662)

Thang SP, Lung MS, Kong G, Hofman MS, Callahan J, Michael M \& Hicks RJ 2018 Peptide receptor radionuclide therapy (PRRT) in European Neuroendocrine Tumour Society (ENETS) grade 3 (G3) neuroendocrine neoplasia (NEN) - a single-institution retrospective analysis. European Journal of Nuclear Medicine and Molecular Imaging 45 262-277. (https://doi.org/10.1007/s00259-017-3821-2)

Tsuruoka K, Horinouchi H, Goto Y, Kanda S, Fujiwara Y, Nokihara H, Yamamoto N, Asakura K, Nakagawa K, Sakurai H, et al. 2017 PD-L1 expression in neuroendocrine tumors of the lung. Lung Cancer $\mathbf{1 0 8}$ 115-120. (https://doi.org/10.1016/j.lungcan.2017.03.006)

Turner NC, Strauss SJ, Sarker D, Gillmore R, Kirkwood A, Hackshaw A, Papadopoulou A, Bell J, Kayani I, Toumpanakis C, Grillo F, et al. 2010 Chemotherapy with 5-fluorouracil, cisplatin and streptozocin for neuroendocrine tumours. British Journal of Cancer 102 1106-1112. (https://doi.org/10.1038/sj.bjc.6605618)
Vélayoudom-Céphise FL, Duvillard P, Foucan L, Hadoux J, Chougnet CN, Leboulleux S, Malka D, Guigay J, Goere D, Debaere T, et al. 2013 Are G3 ENETS neuroendocrine neoplasms heterogeneous? Endocrine-Related Cancer 20 649-657. (https://doi.org/10.1530/ERC13-0027)

Vijayvergia N, Boland PM, Handorf E, Gustafson KS, Gong Y, Cooper HS, Sheriff F, Astsaturov I, Cohen SJ \& Engstrom PF 2016 Molecular profiling of neuroendocrine malignancies to identify prognostic and therapeutic markers: a fox chase cancer center pilot study. British Journal of Cancer 115 564-570.

Weinberg RA 2014 Biology of Cancer, 2nd ed., ch 14 and 15. New York, NY, USA: Garland Science, 2014.

Welin S, Sorbye H, Sebjornsen S, Knappskog S, Busch C \& Oberg K 2011 Clinical effect of temozolomide-based chemotherapy in poorly differentiated endocrine carcinoma after progression on first-line chemotherapy. Cancer 117 4617-4622. (https://doi.org/10.1002/ cncr.26124)

Woischke C, Schaaf CW, Yang HM, Vieth M, Veits L, Geddert H, Märkl B, Stömmer P, Schaeffer DF, Frölich M, et al. 2017 In-depth mutational analyses of colorectal neuroendocrine carcinomas with adenoma or adenocarcinoma components. Modern Pathology 30 95-103. (https://doi.org/10.1038/modpathol.2016.150)

Yachida S, Vakiani E, White CM, Zhong Y, Saunders T, Morgan R, de Wilde RF, Maitra A, Hicks J, Demarzo AM, et al. 2012 Small cell and large cell neuroendocrine carcinomas of the pancreas are genetically similar and distinct from well-differentiated pancreatic neuroendocrine tumors. American Journal of Surgical Pathology 36 173-184. (https://doi.org/10.1097/ PAS.0b013e3182417d36)

Zappalà G, McDonald PG \& Cole SW 2013 Tumor dormancy and the neuroendocrine system: an undisclosed connection? Cancer Metastasis Reviews 32 189-200. (https://doi.org/10.1007/s10555-0129400-x)

Received in final form 15 March 2018

Accepted 18 April 2018

Accepted Preprint published online 18 April 2018 (c) 2018 Society for Endocrinology Published by Bioscientifica Ltd. Printed in Great Britain 